\title{
RISK OF SUBSEQUENT PRIMARY LEUKEMIAS AMONG 69,460 FIVE-YEAR SURVIVORS OF CHILDHOOD CANCER DIAGNOSED FROM 1940-2008 IN EUROPE: A COHORT STUDY WITHIN PANCARESURFUP
}

Rodrigue S Allodji PhD ${ }^{1,2,3}$, Mike M Hawkins MD-PhD¹, Chloe J Bright $\mathrm{PhD}^{1}$, Miranda M FidlerBenaoudia $\mathrm{PhD}^{1,4}$, David L Winter MS¹, Daniela Alessi MD ${ }^{5}$, Brice Fresneau MD ${ }^{2,6}$, Neige Journy $\mathrm{PhD}^{2}$, Vera Morsellino MD-PhD${ }^{7}$, Edit Bárdi MD-PhD ${ }^{8,9}$, Andrea Bautz $\mathrm{MD}^{10}$, Julianne Byrne $\mathrm{PhD}^{11}$, Elizabeth (Lieke) AM Feijen $\mathrm{PhD}^{12,13}$, Jop C Teepen PhD ${ }^{12,13}$, Giao Vu-Bezin $\mathrm{MS}^{2}$, Carole Rubino MD-PhD², Stanislaw Garwicz MD ${ }^{14 \dagger}$, Desiree Grabow PhD ${ }^{15}$, Thorgerdur Gudmundsdottir MD-PhD ${ }^{9,16}$, Joyeeta Guha $\mathrm{PhD}^{1}$, Eva-Maria Hau MD ${ }^{17,18}$, Momcilo Jankovic $\mathrm{MD}^{19}$, Peter Kaatsch MD-PhD ${ }^{15}$, Melanie Kaiser $\mathrm{MS}^{15}$, Helena Linge $\mathrm{PhD}^{14}$, Monica Muraca $\mathrm{MD}^{7}$, Damien Llanas $\mathrm{MS}^{2}$, Cristina Veres $\mathrm{MS}^{2}$, Hilde Øfstaas $\mathrm{MD}^{20}$, Ibrahima Diallo $\mathrm{PhD}^{2}$, Imene Mansouri $\mathrm{MS}^{2}$, Cecile $\mathrm{M}$ Ronckers $P h D^{12,13}$, Roderick Skinner $\mathrm{MD}^{21}$, Monica Terenziani $\mathrm{MD}^{22}$, Finn Wesenberg $\mathrm{MD}^{23}$,

Thomas Wiebe $\mathrm{MD}^{14}$, Carlotta Sacerdote MD-PhD , Zsuzsanna Jakab MD²4, Riccardo Haupt MD , Päivi Lähteenmäki MD-PhD ${ }^{25}$, Lorna Zadravec Zaletel MD ${ }^{26}$, Claudia E Kuehni MD-PhD7,18, Jeanette F Winther MD-PhD ${ }^{10,27}$, Gisela Michel $\mathrm{PhD}^{28}$, Leontien C Kremer MD-PhD ${ }^{12,13}$, Lars Hjorth MD-PhD ${ }^{14}$, Nadia Haddy PhD ${ }^{1,2}$, Florent de Vathaire $\mathrm{PhD}^{2}$, Raoul C Reulen PhD

\footnotetext{
Affiliations:

${ }^{1}$ Centre for Childhood Cancer Survivor Studies, Institute of Applied Health Research, Robert Aitken Building, University of Birmingham, Birmingham, UK.

${ }^{2}$ Cancer and Radiation Team, Center for Research in Epidemiology and Population Health, INSERM U1018, University Paris Saclay, Gustave Roussy, Villejuif, France.

${ }^{3}$ Polytechnic School of Abomey-Calavi (EPAC), University of Abomey-Calavi, 01 P.O. Box 2009, Cotonou, Benin.

${ }^{4}$ Department of Cancer Epidemiology and Prevention Research, Alberta Health Services, Calgary, Alberta, Canada

${ }^{5}$ Childhood Cancer Registry of Piedmont, Cancer Epidemiology Unit, Department of Medical Sciences, University of Turin and AOU Città della Salute e della Scienza di Torino, Italy. ${ }^{6}$ Department of Pediatric oncology, Gustave Roussy, Université Paris-Saclay, Villejuif, France ${ }^{7}$ Epidemiology and Biostatistics Unit, Istituto Giannina Gaslini, Genova, Italy.
} 
${ }^{8} 2^{\text {nd }}$ Department of Pediatrics, Semmelweis University, Budapest, Hungary.

${ }^{9}$ Department of Paediatrics and Adolescent Medicine, Kepler University Hospital, Linz, Austria

${ }^{10}$ Danish Cancer Society Research Center, Childhood Cancer research group, Copenhagen, Denmark.

${ }^{11}$ Boyne Research Institute, Drogheda, Ireland.

${ }^{12}$ Department of Pediatric Oncology, Emma Children's Hospital/Academic Medical Center, Amsterdam, The Netherlands.

${ }^{13}$ Princess Máxima Center for Pediatric Oncology, Utrecht, The Netherlands.

${ }^{14}$ Lund University, Skane University Hospital, Department of Clinical Sciences, Paediatrics, Lund, Sweden.

${ }^{15}$ German Childhood Cancer Registry (GCCR), Institute of Medical Biostatistics, Epidemiology and Informatics, University Medical Center, Mainz, Germany.

${ }^{16}$ Children's Hospital, Landspitali University Hospital, Reykjavik, Iceland.

${ }^{17}$ Swiss Childhood Cancer Registry, Institute of Social and Preventive Medicine, University of Bern, Switzerland.

${ }^{18}$ Department of Paediatrics, University Children's Hospital of Bern, University of Bern, Switzerland

${ }^{19}$ Foundation MBBM, Hemato-Oncology Center, University of Milano-Bicocca, via Cadore 38, 20900 Monza (MB), Italy.

${ }^{20}$ Norwegian National Advisory Unit on solid tumors in children, Norway.

${ }^{21}$ Great North Children's Hospital, Newcastle upon Tyne Hospitals NHS Foundation Trust, and Northern Institute of Cancer Research, Newcastle University, Newcastle upon Tyne, UK.

${ }^{22}$ Pediatric Oncology Unit, Fondazione IRCCS Istituto Nazionale dei Tumori, Milano, Italy.

${ }^{23}$ Norwegian Cancer Registry and Dept. of Pediatric Medicine, Oslo University Hospital and Institute of Clinical Medicine, Faculty of medicine, University of Oslo, Norway.

${ }^{24}$ Hungarian Childhood Cancer Registry, ${ }^{\text {nd }}$ Department of Pediatrics, Semmelweis University, Budapest, Hungary.

${ }^{25}$ Turku University and Turku University Hospital, Department of Pediatric and Adolescent Medicine, Turku, Finland.

${ }^{26}$ Institute of Oncology, Ljubljana, Slovenia.

${ }^{27}$ Department of Clinical Medicine, Faculty of Health, Aarhus University, Aarhus, Denmark.

${ }^{28}$ Department of Health Sciences and Health Policy, University of Lucerne, Frohburgstrasse 3, PO Box 4466, 6002, Lucerne, Switzerland.

${ }^{\dagger}$ Deceased 27 th November 2018 to whom this research is dedicated.

Corresponding author: Dr Rodrigue S. Allodji, Radiation Epidemiology Group / CESP - Unit 1018

INSERM, Gustave Roussy, B2M, 114, rue Édouard Vaillant 94805 Villejuif Cedex, Tel 0142115498 / Fax

0142115618 E-mail: rodrigue.allodii@gustaveroussy.fr / Centre for Childhood Cancer Survivor Studies,

Institute of Applied Health Research, Robert Aitken Building, University of Birmingham, Birmingham, B15

2TT; Tel: +44 (0)121 414 4946; Email: A.Rodrigue@bham.ac.uk

Word counts: abstract 250, main text (excluding references) 2926

References: main text 30 


\section{Tables, 1 Figure in main text}

Abbreviations: PanCare Childhood and Adolescent Cancer Survivor Care and Follow-up Studies (PanCareSurFup); Childhood Cancer Survivor Study (CCSS); standardized incidence ratio (SIR); absolute excess risk (AER); adolescent and young adult (AYA); confidence intervals (Cls); International Classification of Childhood Cancer (ICCC); relative risk (RR); subsequent primary leukemias (SPLs); first primary neoplasm (FPN); subsequent primary myeloid leukemias (SPML) and subsequent primary lymphoid leukemias (SPLL). 


\section{Summary}

Background: Survivors of childhood cancers are at risk of developing subsequent primary leukemias (SPLs), but the long-term risks after beyond 20 years following treatment are still unclear. We investigated the risk of SPLs in five-year childhood cancer survivors using a largescale pan-European (PanCareSurFup) cohort and evaluated variations in the risk by cancer and demographic factors.

Methods: This largest-ever assembled cohort comprises 69,460 five-year childhood cancer survivors from 12 European countries. Standardized incidence ratios (SIRs) and absolute excess risks (AERs) were calculated.

Results: One hundred and fifteen survivors developed a SPL including 86 myeloid leukemias (SPML), 17 lymphoid leukemias and 12 other types of leukemias; of these SPLs, 31(27\%) occurred beyond 20 years from first childhood cancer diagnosis. Compared with the general population, childhood cancer survivors had a 4 -fold increased risk (SIR $=3.7,95 \%$ confidence interval [CI]: 3.1 to 4.5) of developing leukemia, and eight leukemias per 100,000 person-years (AER $=7.5,95 \% \mathrm{Cl}: 6.0$ to 9.2 ) occurred in excess of that expected. The risks remained significantly elevated beyond 20 years from first primary malignancy (SIR $=2.4,95 \%$ Cl: 1.6 to 3.4). Overall, the risk ratio for SPML (SIR $=5.8,95 \% \mathrm{Cl}$ : 4.6 to 7.1 ) was higher than that for other SPLS.

Conclusions: We demonstrate that beyond 20 years after childhood cancer diagnosis, survivors experience an increased risk for SPLs compared to that expected from the general population. Our findings highlight the need for awareness by survivors and their health care providers for potentially risk related to SPL.

Keywords: Childhood cancer survivors; second cancers; subsequent primary leukemia; myeloid leukemias; lymphoid leukemias. 


\section{Introduction}

The survival of children with cancer has improved significantly over the past 60 years, with more than $80 \%$ of individuals diagnosed recently becoming five-year survivors. ${ }^{1}$ Nevertheless, significant long-term morbidities continue to impact the majority of children who survived cancer. One of the most devastating sequelae among childhood cancer survivors (CCSs) is the occurrence of subsequent primary neoplasms. ${ }^{2-8}$ Given that the number of survivors continues to increase, it is imperative that studies are undertaken to improve the understanding of the risks and causes of such late effects of treatments for cancer in order to produce an evidence base to inform clinical guidelines for follow-up.

Subsequent primary leukemias (SPLs), both myeloid and lymphoid leukemias, are a concern for long-term CCSs. Previous investigations have reported that the cumulative incidence of SPLs plateaus between 10 and 15 years after first primary therapy. ${ }^{5,9}$ To our knowledge, information on the risk of developing SPLs after 20 years remains unclear due to inadequate statistical power and follow-up time of those previous studies. For example, among 14,358 five-year survivors from the North American Childhood Cancer Survivor Study cohort, 43 SPLS were observed of which only 13 were diagnosed after 15 years from the original cancer diagnosis. ${ }^{5}$ The pan-European cohort of CCSs (PanCareSurFup) from several European countries offers a unique opportunity to evaluate the risk of SPL in a large population of survivors with a variety of first primary malignancies and long follow-up into adulthood. ${ }^{10-15}$ The principal aim of the current study was to investigate the risk of occurrence of SPLs in five-year CCSs using the large-scale PanCareSurFup cohort and evaluate variations in the risk by cancer and demographic factors.

\section{Methods}

\section{PanCareSurFup cohort}

The PanCare Childhood and Adolescent Cancer Survivor Care and Follow-Up Studies (PanCareSurFup; www.pancaresurfup.eu) consortium pools data from 13 European cohorts, 
within 12 countries, to establish the largest ever collaborative study to comprehensively investigate adverse health outcomes in long-term CCSs. The PanCareSurFup cohort comprises data from both population-based cancer registries and major treatment centers. ${ }^{12,13}$ A total of 69,460 five-year CCSs diagnosed before the age of 20 years between 1940 and 2008 were included in this cohort as previously described. ${ }^{14,15}$

First primary neoplasms (FPN) were grouped according to the International Classification of Childhood Cancer third edition. ${ }^{16}$ Ethical approval was obtained separately for each cohort from the appropriate bodies within each specific country. The main characteristics of the PanCareSurFup cohort are described in Table 1.

\section{Identification and ascertainment of SPLS}

Follow-up for SPLs began at the date of five-year survival. Exit from risk was the first of: date of SPL; date of death (competing risk); date of last follow-up contact; date lost to follow-up. SPLs were coded using the International Classification of Diseases for Oncology (ICD-O) Editions 1, 2 and 3, ${ }^{16-18}$ consistent with other publications analyzing such data (Appendix Table S1, p 1) ${ }^{6-8,19,20}$ These SPLs were ascertained through (or using a combination of): linkage with population-based national cancer registries, follow-up clinics, questionnaires, available medical records, linkage with national mortality registries, and linkage with health insurance registries and validated principally using pathology reports and occasionally other definitive diagnostic reports. ${ }^{14,15}$

\section{Statistical analyses}

To compare the observed number of SPLs with that expected from the general population, general population leukemia incidence rates were classified according to the adolescent and young adult cancer classification based on ICD-O morphology. Incidence rates by ICD-O morphology were available for the United Kingdom (UK) (years 1971-2006: England and Wales, only $)^{21}$ and were used as general population rates also for France, Hungary, Italy, Netherlands, Slovenia and Switzerland. Similarly, Finnish incidence rates by ICD-O morphology (years 1953-2011) were used for Denmark, Norway, Sweden and Iceland. ${ }^{22}$ When 
the range of calendar years for the general population cancer rates did not cover the entire follow up period, rates from the closest available calendar year were used.

Standardized incidence ratios (SIRS) were calculated as the observed number of SPLs divided by the expected number of leukemias. Absolute excess risks (AERs) were calculated as the observed minus the expected number of leukemias, divided by person-years at risk and multiplied by 100,000 . The AER can be interpreted as the number of excess leukemias observed beyond that expected from the general population per 100,000 persons per year. The 95\% confidence intervals (Cls) were calculated assuming that the observed number of SPLs followed a Poisson distribution. SIRs and AERs were stratified by country, sex, type of childhood cancer, age at and decade of childhood FPN diagnosis, attained age at exit, and years of follow-up. Relative risks (RR) and the relative excess risk (RER) of developing SPLs associated with these potential explanatory factors were estimated using univariable and multivariable Poisson regression. RRs may be interpreted as the ratio of SIRs, adjusted for relevant co-factors fitted. Similarly, relative RERs may be interpreted as the ratio of AERs, adjusted for relevant co-factors fitted. Tests of homogeneity and trend were based on likelihood ratio tests. For trend tests, ordinal variables were treated as continuous variables in the model. Lastly, cumulative incidence curves relating to the first occurrence of a SPL, adjusting for death as a competing risk, were calculated and Gray's tests were used to evaluate hypotheses of equality of cumulative incidence functions between subgroups where relevant. All statistical analyses were conducted in SAS software, version 9.4. A two-sided pvalue $<0.05$ was considered statistically significant.

\section{Results}

\section{Cohort characteristics}

Among 69,460 five-year CCSs, a total of 1,126,273 person-years were accrued and 115 SPLS were observed after a median follow-up of 19 years (range 5-67 years) and a median age at childhood cancer diagnosis of 7 (range 0-20 years). Loss-to-follow-up did not exceed 6\% 
(Appendix Table S2, p 2). The most commonly observed SPLs were subsequent primary myeloid leukemias (SPML) [86 SPMLs including 44 acute myeloid leukemias (AML), 10 chronic myeloid leukemias (CML) and 32 unspecified/other myeloid leukemias mainly $\mathrm{AML}$ not otherwise specified (NOS) and myeloid leukemia NOS], followed by subsequent primary lymphoid leukemias (SPLL) [17 SPLLs including 5 acute lymphoid leukemias (ALL), 4 chronic lymphoid leukemias (CLL) and 8 unspecified/other lymphoid leukemias mainly precursor Bcell and precursor T-cell lymphoblastic leukemia]; and other types of leukemias [12 SPLs including 5 acute leukemias NOS, 2 leukemia NOS, 2 hairy cell leukemia and 3 other leukemias] (Appendix Tables S1 and S3, p 1 and 3). Demographic and cancer characteristics of the study cohort are shown in Table 1 . The median attained age at study exit was 28 years (range 5-79 years) and female survivors accounted for $41 \%$ of five-year survivors who developed a SPL. Of those survivors who developed a SPL, 19 (17\%) were originally diagnosed with Hodgkin lymphoma as childhood cancer, despite only $9 \%$ of the survivors in this cohort being diagnosed with Hodgkin lymphoma in the all five-year-survivors. There were $31(27 \%)$ SPLs diagnosed beyond 20 years after the FPN and 15 SPLs diagnosed beyond attained age 40 years (Table 1 ).

\section{First primary neoplasm (FPN) characteristics of survivors with a SPL}

The characteristics of the 115 five-year survivors who developed a SPL are summarized in Table 2 by type of FPN. Among these, 39 (34\%) were diagnosed with their FPN under the age of five years; specifically, $83 \%(5 / 6)$ and $75 \%$ (6/8) of SPLs occurring among neuroblastoma or Wilms tumor survivors were originally diagnosed before age five, respectively (Table 2). The median latency between the FPN and SPL was 10 years (Table 1), with the shortest delay noted for survivors of soft-tissue sarcoma (8 years) and leukemia (9 years). In contrast, survivors whose first malignancy was either Wilms tumor or retinoblastoma had the longest mean latency -17 and 37 years, respectively. The median attained age at SPL diagnosis was 20 years (Table 1 ), while median age at the development of SPL was highest for Hodgkin 
lymphoma (21 years), not classifiable childhood cancers (25 years) and retinoblastoma (41 years) survivors (Table 2).

\section{Overall risk of SPL}

Compared to that expected from the general population, CCSs had an almost 4-fold risk (SIR $3 \cdot 7,95 \% \mathrm{Cl} 3 \cdot 1-4 \cdot 5)$ of developing an SPL, and almost eight leukemias per 100,000 personyears (AER 7.5, 95\% Cl 6.0-9.2) in excess of that expected (Table 3). The cumulative incidence for the development of SPL steadily increased after FPN diagnosis, from 0.1\% (95\% $\mathrm{Cl} 0 \cdot 1-0 \cdot 2)$ at 20 years to $0 \cdot 6 \%(95 \% \mathrm{Cl} 0 \cdot 4-0 \cdot 9)$ at 50 years (Figure $1 \mathrm{a})$.

All survivors of each specific type of primary childhood cancer-except retinoblastoma and bone sarcoma — had both a statistically significantly increased relative (SIR) and absolute (AER) excess risk of developing a SPL, with the greatest excess risks among Hodgkin lymphoma survivors (SIR 7.9, 95\% Cl 4.7-12.3; AER 18.9, 95\% Cl 11.7-30.6) (table 3). However, the large excess risk for Hodgkin lymphoma survivors seen before 20 years followup (SIR of 12.5) disappears with longer follow-up (SIR 1.9, 95\% CI 0.2-6.8). When stratifying into 4 FPN tumor types (leukemia, lymphoma included also the non-Hodgkin Lymphoma (NHL), CNS and others), the cumulative incidence at 20 years was highest among lymphoma survivors $(0 \cdot 3 \%, 95 \% \mathrm{Cl} 0 \cdot 2-0 \cdot 4)$ (Figure $1 b)$.

Although SIRs appeared to be higher among survivors diagnosed in most recent decades ( $p$ trend=0.0002; Tables 3 \& Appendix Table S4, p 4), this finding was not confirmed by multivariable analyses adjusted for country, sex, type of childhood cancer, age at diagnosis, decade of diagnosis, and years from diagnosis at exit ( $p$-trend=0.5180; Table 4). In addition, we observed no significant differences in cumulative incidence of SPL among categories of decade of diagnosis of FPN ( $p=0 \cdot 2797)$ (Figure 1c).

SIRs decreased significantly with increasing attained age at exit ( $p$-trend=0.0002), but were still 2-fold elevated beyond 30 years of age compared to the general population (Table 3 ). Similarly, the SIR declined with time since FPN diagnosis ( $p$-trend $<0.0001$ ) but remained significantly elevated (SIR $2 \cdot 4,95 \% \mathrm{Cl} 1 \cdot 6-3 \cdot 4)$ after 20 years of follow-up (Table 3). The multivariable analysis revealed that SIRs varied substantially with follow-up time from FPN 
diagnosis $(p=0.0018)$ (Table 4). AERs were particularly high between 5-9 years of follow-up (AER $15 \cdot 1,95 \% \mathrm{Cl} 11 \cdot 3-20 \cdot 1$ ) and then declined substantially to $3 \cdot 8$ to $4 \cdot 2$ between 10 to 39 years, and then increased sharply (AER $12 \cdot 7,95 \% \mathrm{Cl} 4 \cdot 8-33 \cdot 9)$ beyond 40 years follow-up (Table 3).

Risks of subsequent primary myeloid leukemias (SPML) and subsequent primary lymphoid leukemias (SPLL)

Differences in the cumulative incidence rates of SPML and SPLL were observed (Figure 1d). Overall, survivors had significantly and substantially elevated risks for myeloid neoplasms, with a relative risk of 6 -fold (SIR $5 \cdot 8,95 \% \mathrm{Cl} 4 \cdot 6-7 \cdot 1)$ and six myeloid leukemias per 100,000 person-years (AER $6 \cdot 3,95 \% \mathrm{Cl} 5 \cdot 0-8 \cdot 0$ ) in excess of that expected (Table 5). Survivors of each specific type of childhood cancer-except retinoblastoma and bone sarcoma—had both a statistically significantly increased SIR and AER for developing a SPML, though Hodgkin lymphoma survivors experienced the greatest SIR and AER (SIR 12.1, 95\% CI 6.9-19.6; AER 16.8, 95\% Cl 10·0-27.9). SPML AERs varied with age at diagnosis. Those diagnosed under the age of five years and over 15 years experienced an excess of four SPMLs per 100,000 person-years, while those diagnosed at ages 5 to 14 years experienced an excess of eight to ten SPMLs per 100,000 person-years. Most SPMLs were diagnosed under the age of 30 years (81.4\%) and $76 \cdot 7 \%$ occurred within 20 years of FPN diagnosis.

In contrast, the SIR was not significantly elevated for lymphocytic leukemia (SIR $1 \cdot 2,95 \% \mathrm{CI}$ $0 \cdot 7-2 \cdot 0)$ and the AER for developing a SPLL was only 0.3 per 100,000 person-years (Appendix Table S5, p 5). No significantly increased SIRs or AERs were noted for SPLLs when stratified by sex, FPN, age at diagnosis, decade of diagnosis, attained age at exit, nor years from diagnosis at exit.

\section{Discussion}

Main findings 
In this largest ever cohort study investigating the risk of SPLs in five-year CCSs, we showed that the risk of developing a SPL remained elevated for at least 20 years from FPN diagnosis and only the risk of SPML is increased and not for SPLL. Due to the collaborative nature of this study, we were able to expand upon previous individual studies from the UK, ${ }^{8}$ France, ${ }^{6}$ Italy, ${ }^{23}$ Nordic countries, ${ }^{19}$ and United States ${ }^{5,20}$ and overcome their limitations of low statistical power. Indeed, compared to the largest previous study investigating SPL risk in CCSs from the North American Childhood Cancer Survivor Study, ${ }^{5}$ we observed three-times the number of SPLs both overall (115 vs. 43) and beyond 15 years from FPN diagnosis (40 vs. 13). As a result, we provide the most robust estimates of SPL risks among CCSs to date, which substantially adds to the literature and will aid the long-term follow-up of CCSs.

The overall SIR was 3.7 for a SPL, which was slightly higher than the SIR from the previous Nordic countries study with 30,880 childhood cancer patients diagnosed between 1943 and 1987 (SIR of 2.8). ${ }^{19}$ However, our SIR was slightly lower than that reported in a previous CCSS publication with 14,358 survivors showing a 6-fold increased risk (SIR 6.3, 95\% Cl 4.6-8.5), ${ }^{5}$ and two previous European papers: a British cohort of 16,422 including CCSs diagnosed between 1962 and 1983 who survived at least one year (SIR of 8) and the French-British Euro2K cohort including 4,204 3-year CCSs diagnosed between 1947 and 1986 (SIR of 7·8). 8,6 This difference could be explained, in part, by the latency of at least 5 years in the present study, whereas the two previous European studies began follow-up at time of FPN diagnosis, 1-year or 3-year survival. ${ }^{6,8,19}$ Although SPL risk is mainly elevated/peaks in the first 5 years, as in the CCSS, ${ }^{5}$ the PanCareSurFup study includes only five-year survivors; therefore all SPLs occurring in the first 5 years after treatment were not considered in the present study. The AER $\geq 20$ years in our study (AER of 4.8 events per 100,000 person-years of follow-up) is higher than that found in a previous analysis (5) $\geq 15$ years in CCSS survivors (AER of 2 per 100,000 person-years).

Previous reports have indicated that the risk of SPL reaches a plateau at approximately 10 years: ${ }^{9}$ here we reported that SIRs and AER are still increased after 10 years, so there is no plateau. 
Furthermore, consistent with previous studies, ${ }^{26-28}$ the highest SPL risks (SIR and AER) were found in Hodgkin lymphoma survivors in this study, mainly before 20 years follow-up. Therefore, the awareness of this risk remains crucial for survivors of Hodgkin lymphoma. ${ }^{29}$ Statistically significant risks (SIRs or AERs) of SPL were also found after leukemia, soft-tissue sarcoma, CNS tumors, non-Hodgkin's lymphoma, neuroblastoma, and Wilms tumor. Clinicians should be aware of these risks during long-term follow-up care of these survivors, given that both chemotherapy (alkylating agents and/or topoisomerase II inhibitors) and radiation therapy can increase the risk of SPL following treatment. ${ }^{5-8}$

\section{Study strengths, limitations and sensitivity analyses}

The main advantages of the current study is its large size with nearly 70,000 survivors and its great the range of follow-up time; as results, we were able to quantify risks of SPL several decade (>20 years) after FPN diagnosis; and to show that increased risk was only seen for SPML and not for SPLL. These had not been possible in previous papers, and thus provides increased reliability in our findings for clinicians and future research. However, an inherent limitation of large scale cohort studies with long durations of follow-up is that it is often not feasible to collect detailed information on exposures. Thus, the main limitation of our study is the lack of treatment information on cumulative radiation dose (dose to active bone marrow), bone marrow transplantation, family history or syndromes, and cumulative chemotherapy dose exposures given as treatment for the childhood cancer; as a result, we were unable to look specifically at the effect of treatment protocols on the risk of SPLs. To address this point, we are currently conducting an international pooled study of all existing cohort and casecontrol studies relating to leukemia after childhood cancer (RadLeuk project). Although smaller in size than the current study, this study will have available cumulative doses of individual cytotoxics and cumulative doses of radiation to the active bone marrow for each individual included. ${ }^{7,8,20,30}$ Therefore, the RadLeuk study should address the risks associated with cumulative radiation and chemotherapeutic doses and development of SPLS. Further research is warranted to assess the influence of family history or syndromes, genetic predispositions, 
genes involved in drug metabolism, and cytogenetic and molecular features, in the development of SPLs. Another limitation is that we did not have general population rates for all the countries included in this study, with only UK or Finnish rates being used for all countries. We have nonetheless performed SIR or AERs sensitivity analyses to determine if the risk estimates reported were sensitive to the general population rates applied, and these additional analyses revealed that excess risk estimates were very similar regardless of the general population rates applied (Appendix Tables S6 and S7, p 6 and 7).

\section{Conclusions}

Our findings show that increased risk was only seen for SPML and not for SPLL. We demonstrate also that the cumulative incidence of SPL does not reach a plateau but continues to increase long after five-year survival, with CCSs experiencing increased risks for SPLS beyond 20 years after their treatment compared to the general population. More efforts are needed to collect information on the long-term risk factors of SPLs in the increasingly large and ageing population of CCSs; such a thorough understanding of the epidemiology of SPLS is essential to identify patients at the highest risk of SPL. Our findings highlight the need for awareness by survivors and their health care providers for potentially risk related to SPL several decade after childhood cancer treatment.

\section{Funding}

This work was supported by the European Union's Seventh Framework Programme for research, technological development and demonstration under PanCareSurFup consortium, funded by EU grant no. 257505. Additional support was received from: The Fondation Force de recherche sur le cancer de I'enfant (FORCE), the Ligue Nationale Contre le Cancer (LNCC-France), The Italian Association for Cancer Research and the Compagnia San Paolo; The Fondo Chiara Rama ONLUS; The Swedish Childhood Cancer Foundation; the ARC French Foundation for cancer research (ARC-France); The French National Agency For Research (ANR) (Hope-Epi project); the French National Cancer Institute (INCA); Pfizer Foundation for Children and Adolescent Health; Slovenian Research Agency; the Swiss 
Paediatric Oncology Group; The Swiss Cancer League (KLS-3412-02-2014, KLS-3886-02-2016); The Swiss Cancer Research foundation (KFS-02783-02-2011); The Swiss National Science Foundation Grant Number (PDFMP3_141775), The Dutch Cancer Society (DCOG2011-5027 and UVA2012-5517), The Norweigen Childhood Cancer Foundation.

These funding agencies had no role in the design and conduct of the study, in the collection, management, analysis and interpretation of the data, or in the preparation, review, and approval of the manuscript.

\section{Acknowledgements}

We are very grateful to the childhood cancer survivors whose information was used for PanCareSurFup. We also would like to thank the following individuals from each country for their contribution to data preparation:

France: Angela Jackson, Florent Dayet, Amar Kahlouche, Fara Diop, Sylvie Challeton, Martine Labbé, Isao Kobayashi, Françoise Terrier.

Italy: Maura Massimino, Francesca Bagnasco, Silvia Caruso, Claudia Casella, Lucia Miligi, Anita Andreano, Andrea Biondi and the AIRTUM working group (see appendix).

The Netherlands: Dutch Childhood Oncology Group LATER; Wim Tissing, Flora van Leeuwen, Marry van den Heuvel-Eibrink, Eline van Dulmen, Jacqueline Loonen, Dorine Bresters, Birgitta Versluys.

Slovenia: Tina Žagar.

Sweden: Ingemar Andersson, Susanne Nordenfelt.

Switzerland: Rahel Kuonen, Elisabeth Kiraly, Gisela Michel, Vera Mitter, Shelagh Redmond and the Swiss Paediatric Oncology Group (www.spog.ch).

UK: Julie Kelly.

The views expressed in this publication are those of the authors and do not necessarily represent those of the funders or collaborating institutions.

\section{Conflicts of Interest}

No conflicts of interest declared. 


\section{References}

1. Gatta G, Zigon G, Capocaccia R, Coebergh JW, et al. Survival of European children and young adults with cancer diagnosed 1995-2002. Eur J Cancer 2009;45:992-1005.

2. Magnani C, Pastore G, Coebergh JW, et al. Trends in survival after childhood cancer in Europe, 1978-1997: report from the Automated Childhood Cancer Information System project (ACCIS). Eur J Cancer 2006;42:1981-2005.

3. Friedman DL, Whitton J, Leisenring W, et al. Subsequent neoplasms in 5-year survivors of childhood cancer: the Childhood Cancer Survivor Study. J Natl Cancer Inst 2010;102:10831095.

4. Reulen RC, Frobisher C, Winter DL, et al. Long-term risks of subsequent primary neoplasms among survivors of childhood cancer. J Am Med Assoc (JAMA) 2011;305:2311-2319.

5. Nottage K, Lanctot J, Li Z, et al. Long-term risk for subsequent leukemia after treatment for childhood cancer: a report from the Childhood Cancer Survivor Study. Blood 2011;117:63156318.

6. Haddy N, Le Deley MC, Samand A, et al. Role of radiotherapy and chemotherapy in the risk of secondary leukaemia after a solid tumour in childhood. Eur J Cancer 2006;42:2757-2764.

7. Allodji RS, Schwartz B, Veres C, et al. Risk of Subsequent Leukemia after a solid tumor in childhood: Impact of bone marrow radiotherapy and chemotherapy. I Int J Radiat Oncol Biol Phys. 2015;93:658-667.

8. Hawkins MM, Wilson LM, Stovall MA, et al. Epipodophyllotoxins, alkylating agents, and radiation and risk of secondary leukaemia after childhood cancer. BMJ 1992;304:951-958.

9. Bhatia S, Yasui Y, Robison L, et al. High risk of subsequent neoplasms continues with extended follow-up of childhood Hodgkin's disease: report from the Late Effects Study Group. J Clin 
Oncol. 2003;21:4386-4394.

10. Hjorth L, Haupt R, Skinner R, et al. Survivorship after childhood cancer: PanCare: A European Network to promote optimal long-term care. Eur J Cancer. 2015 Jul;51(10):1203-1211.

11. Winther JF, Kenborg L, Byrne J, et al. Childhood cancer survivor cohorts in Europe. Acta Oncol. 2015 May;54(5):655-668.

12. Grabow D, Kaiser M, Hjorth L, et al. The PanCareSurFup cohort of 83,333 five-year survivors of childhood cancer - Methodology and results of harmonising data to establish a cohort from 12 European countries. Eur J Epidemiol. 2018;33:335-349.

13. Byrne J, Alessi D, Allodji RS, et al. The PanCareSurFup consortium: research and guidelines to improve lives for survivors of childhood cancer. Eur J Cancer. 2018;103:238-248.

14. Fidler MM, Reulen RC, Winter DL, et al. Risk of Subsequent Bone Cancers Among 69460 FiveYear Survivors of Childhood and Adolescent Cancer in Europe. J Natl Cancer Inst. 2018;110:183-194.

15. Bright CJ, Hawkins MM, Winter DL, et al. Risk of Soft-Tissue Sarcoma Among 69460 Five-Year Survivors of Childhood Cancer in Europe. J Natl Cancer Inst. 2018;110:649-660.

16. International Classification of Diseases for Oncology, first edition. Geneva, World Health Organization 1976.

17. Percy C, Van Holten V, Muir CS, editors. International Classification of Diseases for Oncology, 2nd edition. Geneva, Switzerland: World Health Organization 1992.

18. Steliarova-Foucher E, Stiller C, Lacour B, et al. International Classification of Childhood Cancer, third edition. Cancer 2005;103(7):1457-1467.

19. Olsen JH, Garwicz S, Hertz H, et al. Second malignant neoplasms after cancer in childhood or 
adolescence. Nordic Society of Paediatric Haematology and Oncology Association of the Nordic Cancer Registries. BMJ 1993;307:1030-1036.

20. Tucker MA, Meadows AT, Boice JD, Jr., et al. Leukaemia after therapy with alkylating agents for childhood cancer. J Nat/ Cancer Inst 1987;78:459-464.

21. Office of National Statistics. Cancer Statistics Registrations - Series MB1. London: Stationary Office; 2006.

22. Statistics Finland. Cancer Registrations 2011. Finish Cancer Registry. Cancer registrations 2015. https://syoparekisteri.fi/syopa-suomessa/tarkeimpia-tilastoja

23. Bagnasco F, Caruso S, Andreano A, et al. Late mortality and causes of death among 5-year survivors of childhood cancer diagnosed in the period 1960-1999 and registered in the Italian Off-Therapy Registry. Eur J Cancer. 2019;110:86-97.

24. Pui C, Behm F, Raimondi S, et al. Secondary acute myeloid leukemia in children treated for acute lymphoid leukemia. N Engl J Med. 1989; 321:136-142.

25. Smith M, Rubinstein L, Anderson J, et al. Secondary leukemia or myelodysplastic syndrome after treatment with epipodophyllotoxins. J Clin Oncol. 1999;17:569-577.

26. Pui C, Hancock M, Raimondi S, et al. Myeloid neoplasia in children treated for solid tumours. Lancet. 1990;336:417-421.

27. Sud A, Thomsen H, Sundquist K, et al. Risk of Second Cancer in Hodgkin Lymphoma Survivors and Influence of Family History. J Clin Oncol. 2017;35:1584-1590.

28. Chang ET, Montgomery SM, Richiardi L, et al. Number of siblings and risk of Hodgkin's lymphoma. Cancer Epidemiol Biomarkers Prev. 2004;13:1236-1243.

29. Schaapveld M, Aleman BM, van Eggermond AM, et al. Second Cancer Risk Up to 40 Years after 
Treatment for Hodgkin's Lymphoma. N Engl J Med. 2015;373:2499-2511.

30. Le Deley MC, Leblanc T, Shamsaldin A, et al. Risk of secondary leukaemia after a solid tumour in childhood according to the dose of epipodophyllotoxins and anthracyclines: a case-control study by the Société Française d'Oncologie Pédiatrique. J Clin Oncol. 2003;21:1074-1081. 
Figure 1. Cumulative incidence of new subsequent leukemia diagnosed in survivors from the five-year survivors of childhood cancer of the largest European PCSF study. a) Whole cohort: Solid lines are calculated cumulative incidence values; dashed lines are $95 \% \mathrm{Cls}$. Cumulative incidence curves for the main type of childhood cancer (b), and decade of diagnosis of FPN (c), and by leukemia type (d). 
a)

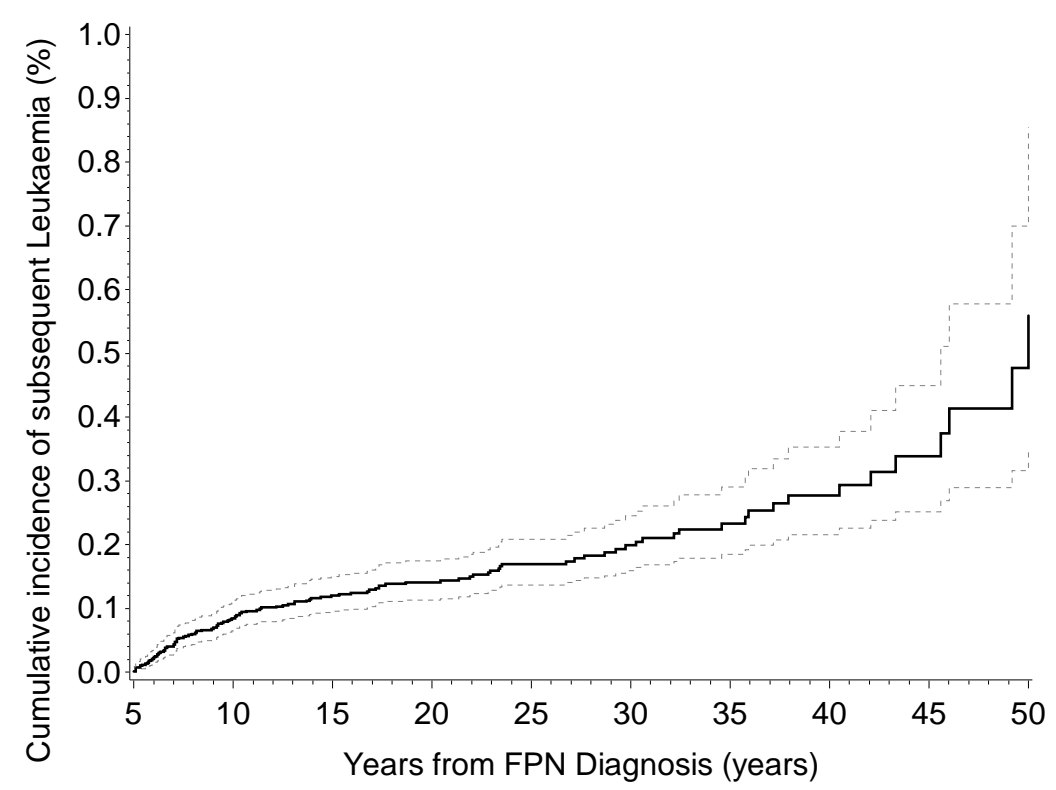

b)

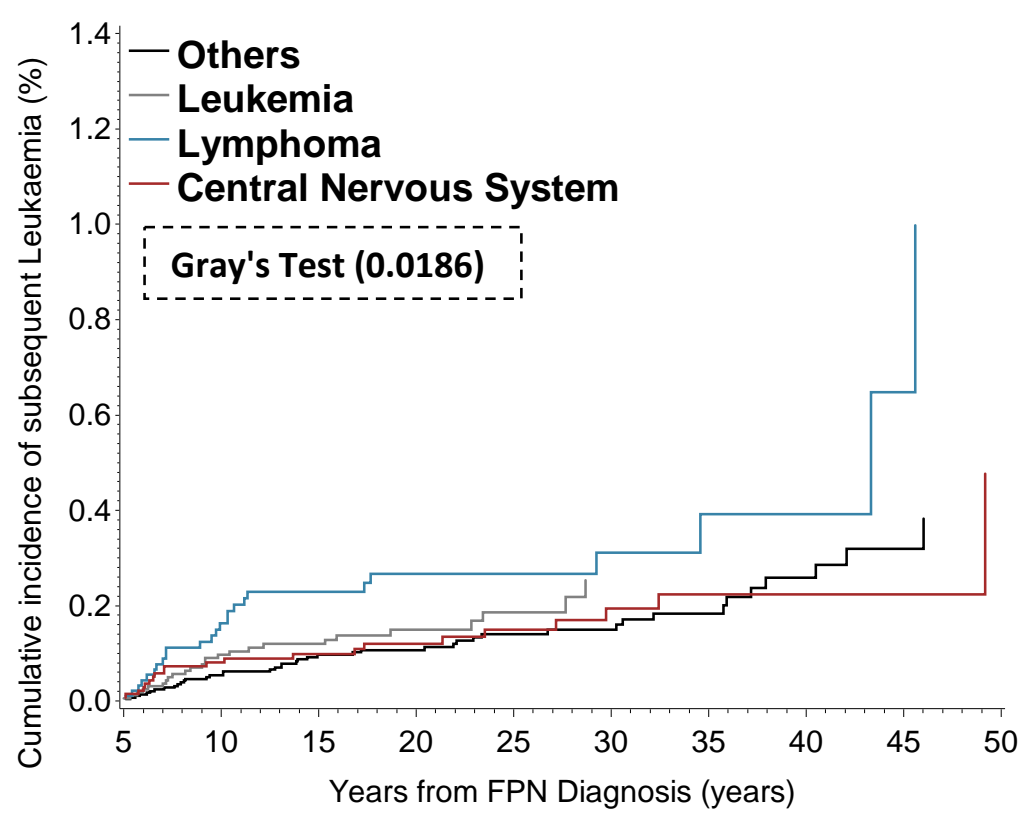

c)

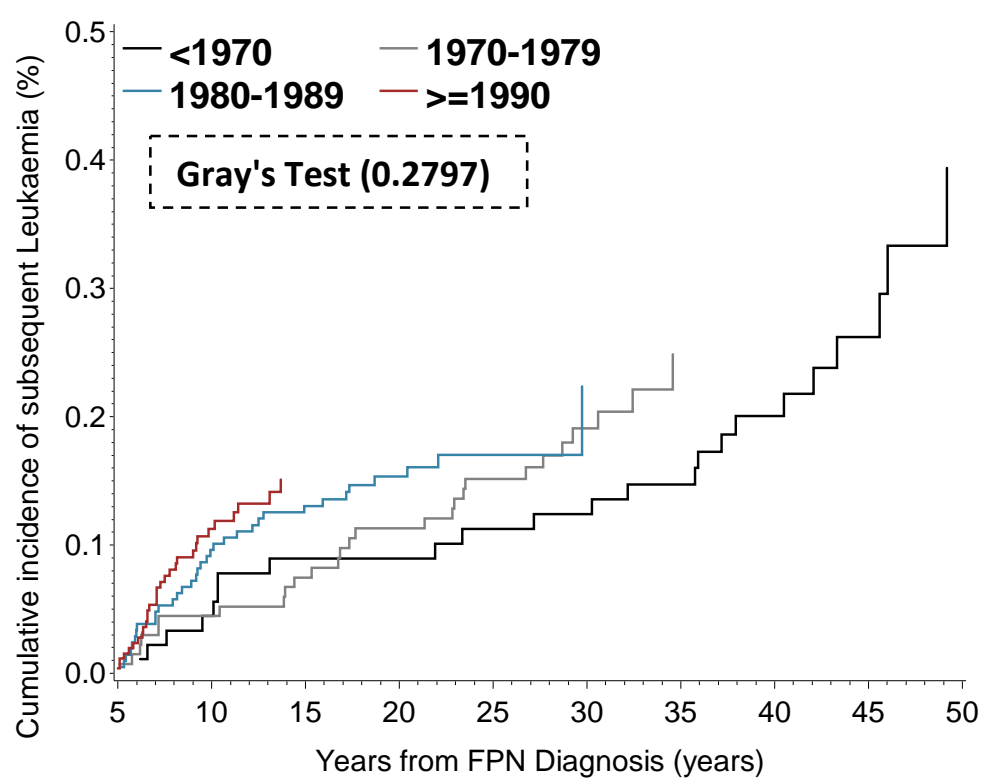

d)



Figure 1. Cumulative incidence of new subsequent leukemia diagnosed in survivors from the five-year survivors of childhood cancer of the largest European PCSF study. a) Whole cohort: Solid lines are calculated cumulative incidence values; dashed lines are $95 \%$ Cls. Cumulative incidence curves for the main type of childhood cancer (b), and decade of diagnosis of FPN (c), and by leukemia type (d). 
Table 1: Characteristics of all 69,460 five-year survivors of childhood cancer of the European PCSF study, 115 survivors who developed a subsequent primary leukemia (SPL) and 7099 survivors who deceased.

\begin{tabular}{|c|c|c|c|c|}
\hline Factors & $\begin{array}{c}\text { All five-year } \\
\text { survivors, } \\
\text { No. (\%) or median } \\
\text { (Range) } \\
\end{array}$ & Person-years & $\begin{array}{c}\text { Survivors who } \\
\text { developed a SLP, } \\
\text { No. (\%) or median } \\
\text { (Range) } \\
\end{array}$ & $\begin{array}{l}\text { Deceased survivors, } \\
\text { No. (\%) or median } \\
\text { (Range) }\end{array}$ \\
\hline Overall & 69,460 & 1126273 & 115 & 7099 \\
\hline \multicolumn{5}{|l|}{ Country } \\
\hline Nordic countries* & $22836(33 \%)$ & 355831 & $29(25 \%)$ & 2235 (31\%) \\
\hline France & $3138(5 \%)$ & 83064 & $9(8 \%)$ & $539(8 \%)$ \\
\hline Hungary & $4885(7 \%)$ & 50100 & $11(10 \%)$ & $350(5 \%)$ \\
\hline Italy & 8966 (13\%) & 94234 & $9(8 \%)$ & $527(7 \%)$ \\
\hline Netherlands & $6044(9 \%)$ & 103229 & $13(11 \%)$ & $491(7 \%)$ \\
\hline Slovenia & $1252(2 \%)$ & 24821 & $3(3 \%)$ & $146(2 \%)$ \\
\hline Switzerland & $4379(6 \%)$ & 46179 & $7(6 \%)$ & $279(4 \%)$ \\
\hline UK & $17960(26 \%)$ & 368816 & $34(30 \%)$ & $2532(36 \%)$ \\
\hline \multicolumn{5}{|l|}{ Sex } \\
\hline Male & 37738 (54\%) & 601424 & 68 (59\%) & 4125 (58\%) \\
\hline Female & $31722(46 \%)$ & 524848 & $47(41 \%)$ & $2974(42 \%)$ \\
\hline \multicolumn{5}{|l|}{ Type of Childhood Cancer } \\
\hline Wilms tumor & $4756(7 \%)$ & 95878 & $8(7 \%)$ & $228(3 \%)$ \\
\hline Leukemia & $16595(24 \%)$ & 219900 & $25(22 \%)$ & $1776(25 \%)$ \\
\hline Hodgkin lymphoma & $6000(9 \%)$ & 87584 & $19(17 \%)$ & $692(10 \%)$ \\
\hline Non-Hodgkin lymphoma & $3350(5 \%)$ & 53752 & $6(5 \%)$ & $196(3 \%)$ \\
\hline Central Nervous System & $14096(20 \%)$ & 228403 & $22(19 \%)$ & $2338(33 \%)$ \\
\hline Neuroblastoma & $3169(5 \%)$ & 55282 & $6(5 \%)$ & $251(4 \%)$ \\
\hline Retinoblastoma & $2578(4 \%)$ & 60224 & $3(3 \%)$ & $87(1 \%)$ \\
\hline Bone sarcoma & $3147(5 \%)$ & 51767 & $3(3 \%)$ & $401(6 \%)$ \\
\hline Soft-tissue sarcoma & $4501(6 \%)$ & 82501 & $8(7 \%)$ & $453(6 \%)$ \\
\hline Other and not classifiable & $11268(16 \%)$ & 190982 & $15(13 \%)$ & $677(10 \%)$ \\
\hline \multicolumn{5}{|l|}{ Age at Diagnosis of FPN } \\
\hline Median (range) & $7(0-20)$ & & $8(0-19)$ & $8(0-20)$ \\
\hline $0-4$ years & $26793(39 \%)$ & 463318 & $39(34 \%)$ & $2232(31 \%)$ \\
\hline $5-9$ years & $15702(23 \%)$ & 255543 & $30(26 \%)$ & $1842(26 \%)$ \\
\hline 10-14 years & $15483(22 \%)$ & 251894 & $34(30 \%)$ & $1890(27 \%)$ \\
\hline $15-19$ years & $11482(17 \%)$ & 155517 & $12(10 \%)$ & 1135 (16\%) \\
\hline \multicolumn{5}{|l|}{ Decade of Diagnosis of FPN } \\
\hline Median (range) & 1986 (1940-2008) & & $1980(1948-2006)$ & 1977 (1940-2008) \\
\hline$<1970$ & $8993(13 \%)$ & 286777 & $24(21 \%)$ & $1989(28 \%)$ \\
\hline 1970-1979 & $13479(19 \%)$ & 313456 & $27(23 \%)$ & 2204 (31\%) \\
\hline 1980-1989 & $20900(30 \%)$ & 339267 & $34(30 \%)$ & $1858(26 \%)$ \\
\hline$\geq 1990$ & $26088(38 \%)$ & 186772 & $30(26 \%)$ & $1048(15 \%)$ \\
\hline \multicolumn{5}{|l|}{ Attained Age at exit } \\
\hline Median (range) & $28(5-79)$ & & $20(6-65)$ & $20(5-76)$ \\
\hline $5-19$ years & $16243(23 \%)$ & 408724 & $56(49 \%)$ & $3521(50 \%)$ \\
\hline $20-29$ years & $22437(32 \%)$ & 389276 & $33(29 \%)$ & $2089(29 \%)$ \\
\hline 30-39 years & $17471(25 \%)$ & 214076 & $11(10 \%)$ & 798 (11\%) \\
\hline$\geq 40$ years & $13309(19 \%)$ & 114196 & $15(13 \%)$ & $691(10 \%)$ \\
\hline \multicolumn{5}{|l|}{ Years from FPN Diagnosis ${ }^{\neq}$} \\
\hline Median (range) & $19(5-67)$ & & $10(5-50)$ & $9(5-63)$ \\
\hline $5-9$ years & $13211(19 \%)$ & 311750 & $55(48 \%)$ & 3860 (54\%) \\
\hline 10-19 years & $23083(33 \%)$ & 449578 & $29(25 \%)$ & $1752(25 \%)$ \\
\hline $20-29$ years & $17602(25 \%)$ & 236989 & $15(13 \%)$ & $816(11 \%)$ \\
\hline 30-39 years & $10290(15 \%)$ & 96627 & $9(8 \%)$ & $454(6 \%)$ \\
\hline$\geq 40$ years & $5274(8 \%)$ & 31328 & $7(6 \%)$ & $217(3 \%)$ \\
\hline
\end{tabular}

${ }^{\star}$ Nordic countries include Finland, Iceland, Norway, Sweden, and Denmark. FPN = first primary neoplasm; ${ }^{\neq}$Years from FPN Diagnosis $=$Years between FPN diagnosis and SPL diagnosis or date at exit. 
Table 2: Characteristics of 115 five-year survivors of childhood cancer of the European PCSF study who developed a subsequent primary leukemia (SPL) according the first primary neoplasm (FPN).

\begin{tabular}{|c|c|c|c|c|c|c|c|c|c|c|}
\hline & $\begin{array}{l}\text { Wilms } \\
\text { tumor } \\
\text { No. (\%) }\end{array}$ & $\begin{array}{l}\text { Leukemia } \\
\text { No. (\%) }\end{array}$ & $\begin{array}{l}\text { Hodgkin } \\
\text { lymphoma } \\
\text { No. (\%) }\end{array}$ & $\begin{array}{l}\text { Non-Hodgkin } \\
\text { Iymphoma } \\
\text { No. (\%) }\end{array}$ & $\begin{array}{c}\text { Central } \\
\text { Nervous } \\
\text { System No. } \\
(\%)\end{array}$ & $\begin{array}{c}\text { Neuroblastoma } \\
\text { No. (\%) }\end{array}$ & $\begin{array}{c}\text { Retinoblastoma } \\
\text { No. (\%) }\end{array}$ & $\begin{array}{c}\text { Bone } \\
\text { sarcoma } \\
\text { No. (\%) }\end{array}$ & $\begin{array}{l}\text { Soft-tissue } \\
\text { sarcoma } \\
\text { No. (\%) }\end{array}$ & $\begin{array}{c}\text { Other and } \\
\text { not } \\
\text { classifiable } \\
\text { No. (\%) }\end{array}$ \\
\hline Overall & 8 & 25 & 19 & 6 & 22 & 6 & 3 & 3 & 8 & 15 \\
\hline \multicolumn{11}{|l|}{$\begin{array}{l}\text { Age at Diagnosis } \\
\text { of FPN }\end{array}$} \\
\hline Median (range) & $2(1-7)$ & $7(1-14)$ & $13(4-18)$ & $9(6-14)$ & $9(2-16)$ & $2(1-6)$ & $1(1-10)$ & $10(5-13)$ & $3(0-10)$ & $9(1-19)$ \\
\hline $0-4$ years & $6(75 \%)$ & $9(36 \%)$ & $1(5 \%)$ & - & $7(32 \%)$ & $5(83 \%)$ & $2(67 \%)$ & $1(33 \%)$ & $5(63 \%)$ & $3(20 \%)$ \\
\hline $5-9$ years & $2(25 \%)$ & $10(40 \%)$ & $1(5 \%)$ & $3(50 \%)$ & $5(23 \%)$ & $1(17 \%)$ & - & - & $3(38 \%)$ & $5(33 \%)$ \\
\hline 10-14 years & - & $6(24 \%)$ & $13(68 \%)$ & $3(50 \%)$ & $8(36 \%)$ & - & $1(33 \%)$ & $2(67 \%)$ & - & $1(7 \%)$ \\
\hline 15-19 years & - & - & $4(21 \%)$ & - & $2(9 \%)$ & - & - & - & - & $6(40 \%)$ \\
\hline \multicolumn{11}{|l|}{$\begin{array}{l}\text { Decade of } \\
\text { Diagnosis of FPN }\end{array}$} \\
\hline Median (range) & $\begin{array}{c}1975 \\
(1954-1989)\end{array}$ & $\begin{array}{c}1986 \\
(1971-2000)\end{array}$ & $\begin{array}{c}1980 \\
(1948-1996)\end{array}$ & $\begin{array}{c}1980 \\
(1963-1991)\end{array}$ & $\begin{array}{c}1989 \\
(1957-2006)\end{array}$ & $\begin{array}{c}1980 \\
(1961-1997)\end{array}$ & $\begin{array}{c}1968 \\
(1953-1980)\end{array}$ & $\begin{array}{c}1970 \\
(1959-1986)\end{array}$ & $\begin{array}{c}1992 \\
(1966-2004)\end{array}$ & $\begin{array}{c}1968 \\
(1954-2001)\end{array}$ \\
\hline$<1970$ & $2(25 \%)$ & - & $4(21 \%)$ & $1(17 \%)$ & $3(14 \%)$ & $2(33 \%)$ & $2(67 \%)$ & $1(33 \%)$ & $1(13 \%)$ & $8(53 \%)$ \\
\hline 1970-1979 & $4(50 \%)$ & $8(32 \%)$ & $5(26 \%)$ & $2(33 \%)$ & $4(18 \%)$ & $1(17 \%)$ & - & $1(33 \%)$ & $1(13 \%)$ & $1(7 \%)$ \\
\hline 1980-1989 & $2(25 \%)$ & $10(40 \%)$ & $8(42 \%)$ & $2(33 \%)$ & $4(18 \%)$ & $1(17 \%)$ & $1(33 \%)$ & $1(33 \%)$ & $2(25 \%)$ & $3(20 \%)$ \\
\hline$\geq 1990$ & - & $7(28 \%)$ & $2(11 \%)$ & $1(17 \%)$ & $11(50 \%)$ & $2(33 \%)$ & - & - & $4(50 \%)$ & $3(20 \%)$ \\
\hline \multicolumn{11}{|l|}{$\begin{array}{l}\text { Age at SPL } \\
\text { Diagnosis }\end{array}$} \\
\hline Median (range) & $20(10-32)$ & $19(10-31)$ & $21(13-59)$ & $17(13-57)$ & $20(8-65)$ & $15(7-43)$ & $41(21-47)$ & $20(12-40)$ & $16(6-36)$ & $25(11-65)$ \\
\hline 5-19 years & $4(50 \%)$ & $14(56 \%)$ & $6(32 \%)$ & $4(67 \%)$ & $11(50 \%)$ & $4(67 \%)$ & - & $1(33 \%)$ & $7(88 \%)$ & $5(33 \%)$ \\
\hline 20-29 years & $3(38 \%)$ & $10(40 \%)$ & $10(53 \%)$ & - & $4(18 \%)$ & - & $1(33 \%)$ & $1(33 \%)$ & - & $4(27 \%)$ \\
\hline 30-39 years & $1(13 \%)$ & $1(4 \%)$ & $1(5 \%)$ & - & $4(18 \%)$ & $1(17 \%)$ & - & - & $1(13 \%)$ & $2(13 \%)$ \\
\hline$\geq 40$ years & - & - & $2(11 \%)$ & $2(33 \%)$ & $3(14 \%)$ & $1(17 \%)$ & $2(67 \%)$ & $1(33 \%)$ & - & $4(27 \%)$ \\
\hline \multicolumn{11}{|l|}{$\begin{array}{l}\text { Years from FPN } \\
\text { Diagnosis }^{\neq}\end{array}$} \\
\hline Median (range) & $17(9-31)$ & $9(5-29)$ & $9(5-46)$ & $10(5-43)$ & $10(5-50)$ & $10(5-42)$ & $37(20-41)$ & $10(8-27)$ & $8(5-36)$ & $13(6-46)$ \\
\hline $5-9$ years & $1(13 \%)$ & $15(60 \%)$ & $11(58 \%)$ & $3(50 \%)$ & $11(50 \%)$ & $3(50 \%)$ & - & $1(33 \%)$ & $5(63 \%)$ & $5(33 \%)$ \\
\hline 10-19 years & $4(50 \%)$ & $6(24 \%)$ & $6(32 \%)$ & $1(17 \%)$ & $4(18 \%)$ & $1(17 \%)$ & - & $1(33 \%)$ & $2(25 \%)$ & $4(27 \%)$ \\
\hline $20-29$ years & $2(25 \%)$ & $4(16 \%)$ & - & $1(17 \%)$ & $4(18 \%)$ & - & $1(33 \%)$ & $1(33 \%)$ & - & $2(13 \%)$ \\
\hline 30-39 years & $1(13 \%)$ & - & $1(5 \%)$ & - & $1(5 \%)$ & $1(17 \%)$ & $1(33 \%)$ & - & $1(13 \%)$ & $3(20 \%)$ \\
\hline$\geq 40$ years & - & - & $1(5 \%)$ & $1(17 \%)$ & $2(9 \%)$ & $1(17 \%)$ & $1(33 \%)$ & - & - & $1(7 \%)$ \\
\hline
\end{tabular}

No. $=$ frequency; $F P N=$ first primary neoplasm; $S P L=$ subsequent primary leukemia. ${ }^{\ddagger}$ Years from FPN Diagnosis $=$ Years between FPN diagnosis and SPL diagnosis 
Table 3: SIRs and AERs per 100,000 person-years at risk of developing a subsequent primary leukemia (SPL) among 69,460 five-year survivors of childhood cancer of the European PCSF study.

\begin{tabular}{|c|c|c|c|c|c|c|c|c|c|}
\hline \multirow{3}{*}{ Factor } & \multirow{2}{*}{\multicolumn{3}{|c|}{ Overall }} & \multicolumn{6}{|c|}{ By years from diagnosis } \\
\hline & & & & \multicolumn{3}{|c|}{ 5-19 years } & \multicolumn{3}{|c|}{$\geq 20$ years } \\
\hline & O/E & SIR (95\% CI) & AER (95\% CI) & O/E & SIR (95\% CI) & AER (95\% CI) & O/E & SIR (95\% CI) & AER $(95 \% \mathrm{Cl})$ \\
\hline Overall & $115 \cdot 0 / 31 \cdot 0$ & $3.7(3.1-4.5)$ & $7 \cdot 5(6 \cdot 0-9 \cdot 2)$ & $84 \cdot 0 / 17 \cdot 9$ & $4 \cdot 7(3 \cdot 7-5 \cdot 8)$ & $8.7(6.8-11.0)$ & $31 \cdot 0 / 13 \cdot 1$ & $2 \cdot 4(1.6-3.4)$ & $4.9(3.1-7 \cdot 8)$ \\
\hline P-values & & $<.0001$ & 0.0073 & & $<.0001$ & 0.0084 & & $<.0001$ & 0.0152 \\
\hline \multicolumn{10}{|l|}{ Country } \\
\hline Nordic countries $¥$ & $29 \cdot 0 / 10 \cdot 9$ & $2.7(1.8-3 \cdot 8)$ & $5 \cdot 1(3 \cdot 2-8 \cdot 1)$ & $20 \cdot 0 / 5 \cdot 7$ & $3.5(2 \cdot 2-5 \cdot 4)$ & $6 \cdot 1(3 \cdot 6-10 \cdot 2)$ & $9 \cdot 0 / 5 \cdot 2$ & $1.7(0.8-3.3)$ & $3.1(1.1-8.6)$ \\
\hline France & $9 \cdot 0 / 2 \cdot 3$ & $3.9(1.8-7.4)$ & $8.0(3 \cdot 8-17 \cdot 2)$ & $5 \cdot 0 / 1 \cdot 0$ & $5.0(1.6-11.8)$ & $9 \cdot 3(3 \cdot 5-24 \cdot 7)$ & $4 \cdot 0 / 1 \cdot 3$ & $3.0(0.8-7 \cdot 7)$ & $6.7(2 \cdot 0-22 \cdot 2)$ \\
\hline Hungary & $11 \cdot 0 / 1 \cdot 2$ & $9.0(4 \cdot 5-16 \cdot 1)$ & $19.5(10 \cdot 4-36 \cdot 5)$ & $10 \cdot 0 / 1 \cdot 0$ & $9 \cdot 8(4 \cdot 7-18 \cdot 0)$ & $21.5(11 \cdot 2-41 \cdot 3)$ & $1 \cdot 0 / 0 \cdot 2$ & $5.0(0.1-28 \cdot 1)$ & $9.7(1.1-86.5)$ \\
\hline Italy & $9 \cdot 0 / 2 \cdot 3$ & $3.9(1.8-7.4)$ & $7 \cdot 1(3 \cdot 3-15 \cdot 1)$ & $8 \cdot 0 / 1 \cdot 8$ & $4.5(1.9-8.8)$ & $8.2(3.7-18 \cdot 0)$ & $1 \cdot 0 / 0 \cdot 5$ & $1.9(0.0-10.6)$ & $2.5(0.1-43.8)$ \\
\hline Netherlands & $13 \cdot 0 / 2 \cdot 6$ & $5.0(2 \cdot 7-8 \cdot 6)$ & $10 \cdot 1(5 \cdot 5-18 \cdot 5)$ & $11 \cdot 0 / 1 \cdot 8$ & $6 \cdot 2(3 \cdot 1-11 \cdot 2)$ & $12 \cdot 4(6 \cdot 5-23 \cdot 7)$ & $2 \cdot 0 / 0 \cdot 8$ & $2.5(0.3-8.9)$ & $4 \cdot 1(0 \cdot 7-24 \cdot 8)$ \\
\hline Slovenia & $3 \cdot 0 / 0 \cdot 7$ & $4.3(0.9-12.4)$ & $9 \cdot 2(2 \cdot 5-33 \cdot 7)$ & $3 \cdot 0 / 0 \cdot 4$ & $8.3(1.7-24.2)$ & $16.7(5.0-55.9)$ & $0 \cdot 0 / 0 \cdot 3$ & - & - \\
\hline Switzerland & $7 \cdot 0 / 1 \cdot 2$ & $6 \cdot 1(2 \cdot 4-12 \cdot 5)$ & $12 \cdot 7(5 \cdot 6-28 \cdot 5)$ & $7 \cdot 0 / 1 \cdot 0$ & $7 \cdot 2(2 \cdot 9-14 \cdot 8)$ & $15 \cdot 1(6 \cdot 8-33 \cdot 5)$ & $0 \cdot 0 / 0 \cdot 2$ & - & - \\
\hline UK & $34 \cdot 0 / 9 \cdot 9$ & $3.5(2 \cdot 4-4 \cdot 8)$ & $6.5(4.4-9.8)$ & $20 \cdot 0 / 5 \cdot 4$ & $3.7(2 \cdot 3-5 \cdot 8)$ & $6 \cdot 2(3 \cdot 7-10 \cdot 4)$ & $14 \cdot 0 / 4 \cdot 5$ & $3 \cdot 1(1 \cdot 7-5 \cdot 2)$ & $7 \cdot 1(3 \cdot 8-13 \cdot 4)$ \\
\hline$P$ for heterogeneity* & & 0.0393 & 0.0444 & & 0.1393 & 0.0453 & & 0.9183 & 0.7732 \\
\hline \multicolumn{10}{|l|}{ Sex } \\
\hline Male & $68 \cdot 0 / 18 \cdot 8$ & $3.6(2.8-4.6)$ & $8.2(6 \cdot 2-10 \cdot 8)$ & $47 \cdot 0 / 11 \cdot 1$ & $4 \cdot 2(3 \cdot 1-5 \cdot 6)$ & $8 \cdot 8(6 \cdot 3-12 \cdot 2)$ & $21 \cdot 0 / 7 \cdot 7$ & $2 \cdot 7(1.7-4 \cdot 2)$ & $6.9(4.0-11.9)$ \\
\hline Female & $47 \cdot 0 / 12 \cdot 2$ & $3.9(2.9-5.2)$ & $6 \cdot 6(4 \cdot 8-9 \cdot 3)$ & $37 \cdot 0 / 6 \cdot 8$ & $5.4(3.8-7 \cdot 5)$ & $8.6(6 \cdot 0-12 \cdot 3)$ & $10 \cdot 0 / 5 \cdot 4$ & $1.9(0.9-3.4)$ & $2 \cdot 7(1.1-6 \cdot 6)$ \\
\hline$P$ for heterogeneity* & & 0.7324 & 0.3446 & & 0.2561 & 0.9348 & & 0.3207 & 0.0771 \\
\hline \multicolumn{10}{|l|}{ Type of Childhood Cancer } \\
\hline Wilms tumor & $8 \cdot 0 / 2 \cdot 5$ & $3.2(1.4-6.4)$ & $5 \cdot 8(2 \cdot 5-13 \cdot 3)$ & $5 \cdot 0 / 1 \cdot 5$ & $3.4(1 \cdot 1-7 \cdot 8)$ & $5.9(2 \cdot 1-16 \cdot 7)$ & $3 \cdot 0 / 1 \cdot 0$ & $3.1(0.6-8.9)$ & $5.6(1.4-22 \cdot 2)$ \\
\hline Leukemia & $25 \cdot 0 / 5 \cdot 4$ & $4.7(3.0-6 \cdot 9)$ & $8.9(5 \cdot 7-13 \cdot 9)$ & $21 \cdot 0 / 4 \cdot 2$ & $5 \cdot 0(3 \cdot 1-7 \cdot 7)$ & $9 \cdot 8(6 \cdot 1-15 \cdot 8)$ & $4 \cdot 0 / 1 \cdot 2$ & $3.4(0.9-8.7)$ & $5.9(1.8-18.8)$ \\
\hline Hodgkin lymphoma & $19 \cdot 0 / 2 \cdot 4$ & $7 \cdot 9(4 \cdot 7-12 \cdot 3)$ & $18.9(11 \cdot 7-30 \cdot 6)$ & $17 \cdot 0 / 1 \cdot 4$ & $12 \cdot 5(7 \cdot 3-20 \cdot 0)$ & $25 \cdot 3(15 \cdot 4-41 \cdot 5)$ & $2 \cdot 0 / 1 \cdot 1$ & $1.9(0.2-6.8)$ & $3.7(0.5-27 \cdot 7)$ \\
\hline Non-Hodgkin Iymphoma & $6 \cdot 0 / 1 \cdot 5$ & $3.9(1.4-8.4)$ & $8.3(3.3-21.0)$ & $4 \cdot 0 / 0 \cdot 9$ & $4.6(1.2-11.7)$ & $8.4(2.8-25.5)$ & $2 \cdot 0 / 0 \cdot 7$ & $3.0(0.4-10.7)$ & $7.9(1.4-43.6)$ \\
\hline Central Nervous System & $22 \cdot 0 / 6 \cdot 4$ & $3.5(2.2-5 \cdot 2)$ & $6.8(4.2-11.2)$ & $15 \cdot 0 / 3 \cdot 5$ & $4 \cdot 3(2 \cdot 4-7 \cdot 1)$ & $7 \cdot 6(4 \cdot 2-13 \cdot 5)$ & $7 \cdot 0 / 2 \cdot 9$ & $2.4(1.0-5 \cdot 0)$ & $5.4(2 \cdot 1-14 \cdot 2)$ \\
\hline Neuroblastoma & $6 \cdot 0 / 1 \cdot 5$ & $4.1(1.5-8.9)$ & $8.2(3.3-20.6)$ & $4 \cdot 0 / 1 \cdot 0$ & $4 \cdot 1(1 \cdot 1-10 \cdot 6)$ & $8.4(2 \cdot 7-26 \cdot 0)$ & $2 \cdot 0 / 0 \cdot 5$ & $4.0(0.5-14.6)$ & $7.8(1.6-38 \cdot 4)$ \\
\hline Retinoblastoma & $3 \cdot 0 / 1 \cdot 7$ & $1.8(0.4-5.3)$ & $2 \cdot 2(0.4-12 \cdot 1)$ & $0.0 / 0.9$ & - & - & $3 \cdot 0 / 0 \cdot 8$ & $3.8(0.8-11.1)$ & $8.2(2 \cdot 2-30 \cdot 6)$ \\
\hline Bone sarcoma & $3 \cdot 0 / 1 \cdot 6$ & $1.9(0.4-5.6)$ & $2 \cdot 8(0.5-14 \cdot 2)$ & $2 \cdot 0 / 0 \cdot 7$ & $2.7(0.3-9.9)$ & $3.7(0.7-21.4)$ & $1 \cdot 0 / 0 \cdot 8$ & $1.2(0.0-6.6)$ & $0.9(0.0-124)$ \\
\hline Soft-tissue sarcoma & $8 \cdot 0 / 2 \cdot 4$ & $3.3(1.4-6.4)$ & $6.7(2 \cdot 9-15 \cdot 5)$ & $7 \cdot 0 / 1 \cdot 2$ & $5 \cdot 7(2 \cdot 3-11 \cdot 8)$ & $11 \cdot 2(4 \cdot 9-25 \cdot 3)$ & $1 \cdot 0 / 1 \cdot 2$ & $0.8(0.0-4.6)$ & - \\
\hline Other and not classifiable & $15 \cdot 0 / 5 \cdot 7$ & $2.6(1.5-4.3)$ & $4.9(2 \cdot 5-9 \cdot 2)$ & $9 \cdot 0 / 2 \cdot 8$ & $3.3(1.5-6.2)$ & $5 \cdot 0(2 \cdot 3-11 \cdot 0)$ & $6 \cdot 0 / 3 \cdot 0$ & $2.0(0.7-4.4)$ & $4.5(1.5-13.9)$ \\
\hline$P$ for heterogeneity ${ }^{\star}$ & & 0.0550 & 0.0202 & & 0.0392 & 0.0120 & & 0.9256 & 0.9927 \\
\hline \multicolumn{10}{|l|}{ Age at Diagnosis of FPN } \\
\hline $0-4$ years & $39 \cdot 0 / 12 \cdot 2$ & $3 \cdot 2(2 \cdot 3-4 \cdot 4)$ & $5.8(4.0-8.5)$ & $26 \cdot 0 / 8 \cdot 2$ & $3 \cdot 2(2 \cdot 1-4 \cdot 7)$ & $5 \cdot 8(3.6-9 \cdot 2)$ & $13 \cdot 0 / 4 \cdot 1$ & $3.2(1.7-5 \cdot 5)$ & $5 \cdot 8(3 \cdot 0-11 \cdot 1)$ \\
\hline $5-9$ years & $30 \cdot 0 / 6 \cdot 5$ & $4.6(3.1-6.6)$ & $9 \cdot 2(6 \cdot 1-13 \cdot 8)$ & $25 \cdot 0 / 3 \cdot 9$ & $6 \cdot 4(4 \cdot 1-9 \cdot 4)$ & $12 \cdot 1(7 \cdot 9-18 \cdot 6)$ & $5 \cdot 0 / 2 \cdot 6$ & $1.9(0.6-4.5)$ & $2.9(0.8-10.4)$ \\
\hline 10-14 years & $34 \cdot 0 / 7 \cdot 2$ & $4.8(3.3-6.6)$ & $10 \cdot 7(7 \cdot 3-15 \cdot 6)$ & $26 \cdot 0 / 3 \cdot 5$ & $7 \cdot 4(4 \cdot 8-10 \cdot 8)$ & $13.2(8.7-20.0)$ & $8 \cdot 0 / 3 \cdot 6$ & $2.2(0.9-4.3)$ & $5.3(2.1-13.6)$ \\
\hline 15-19 years & $12 \cdot 0 / 5 \cdot 1$ & $2 \cdot 3(1 \cdot 2-4 \cdot 1)$ & $4.4(2 \cdot 1-9 \cdot 3)$ & $7 \cdot 0 / 2 \cdot 3$ & $3.0(1.2-6.2)$ & $4.3(1.7-10 \cdot 6)$ & $5 \cdot 0 / 2 \cdot 8$ & $1.8(0.6-4.1)$ & $4 \cdot 8(1 \cdot 3-17 \cdot 9)$ \\
\hline
\end{tabular}


Published in final edited form as: Eur J Cancer. 2019 Aug;117:71-83. doi: 10.1016/j.ejca.2019.05.013

\begin{tabular}{|c|c|c|c|c|c|c|c|c|c|}
\hline$P$ for heterogeneity ${ }^{*}$ & & 0.0780 & 0.0487 & & 0.0059 & 0.0113 & & 0.6070 & 0.8302 \\
\hline$P$-trend* & & 0.9746 & 0.5241 & & 0.1621 & 0.4339 & & 0.2485 & 0.8047 \\
\hline \multicolumn{10}{|c|}{ Decade of Diagnosis of FPN } \\
\hline$<1970$ & $24 \cdot 0 / 10 \cdot 4$ & $2 \cdot 3(1.5-3 \cdot 4)$ & $4 \cdot 7(2 \cdot 8-8 \cdot 1)$ & $8 \cdot 0 / 2 \cdot 7$ & $3.0(1 \cdot 3-5 \cdot 9)$ & $4.5(1.9-10 \cdot 4)$ & $16 \cdot 0 / 7 \cdot 7$ & $2 \cdot 1(1 \cdot 2-3 \cdot 4)$ & $4.9(2.5-9.8)$ \\
\hline 1970-1979 & $27 \cdot 0 / 7 \cdot 9$ & $3 \cdot 4(2 \cdot 3-5 \cdot 0)$ & $6.1(3.9-9.5)$ & $15 \cdot 0 / 4 \cdot 1$ & $3 \cdot 7(2 \cdot 0-6 \cdot 0)$ & $6 \cdot 0(3 \cdot 3-10 \cdot 9)$ & $12 \cdot 0 / 3 \cdot 8$ & $3.2(1 \cdot 6-5 \cdot 5)$ & $6 \cdot 2(3 \cdot 1-12 \cdot 3)$ \\
\hline 1980-1989 & $34 \cdot 0 / 8 \cdot 1$ & $4.2(2.9-5.9)$ & $7 \cdot 6(5 \cdot 2-11 \cdot 2)$ & $31 \cdot 0 / 6 \cdot 5$ & $4.7(3 \cdot 2-6 \cdot 7)$ & $8.9(6 \cdot 0-13 \cdot 2)$ & $3.0 / 1.5$ & $2.0(0.4-5.8)$ & $2.3(0.5-11.7)$ \\
\hline$\geq 1990$ & $30 \cdot 0 / 4 \cdot 7$ & $6 \cdot 4(4 \cdot 3-9 \cdot 2)$ & $13.6(9 \cdot 2-20 \cdot 0)$ & $30 \cdot 0 / 4 \cdot 6$ & $6 \cdot 5(4 \cdot 4-9 \cdot 3)$ & $13 \cdot 8(9 \cdot 3-20 \cdot 3)$ & $0.0 / 0 \cdot 0$ & - & - \\
\hline P for heterogeneity* & & 0.0020 & 0.0066 & & $0 \cdot 1317$ & 0.0303 & & 0.7058 & 0.5400 \\
\hline P-trend* & & 0.0002 & 0.0012 & & 0.0200 & 0.0033 & & 0.7007 & 0.6018 \\
\hline \multicolumn{10}{|l|}{ Attained Age at exit } \\
\hline $5-19$ years & $56 \cdot 0 / 10 \cdot 8$ & $5 \cdot 2(3 \cdot 9-6 \cdot 7)$ & $11.1(8 \cdot 3-14 \cdot 8)$ & $56 \cdot 0 / 10 \cdot 8$ & $5 \cdot 2(3 \cdot 9-6 \cdot 7)$ & $11 \cdot 1(8 \cdot 3-14 \cdot 8)$ & - & - & \\
\hline $20-29$ years & $33 \cdot 0 / 7 \cdot 7$ & $4 \cdot 3(3 \cdot 0-6 \cdot 0)$ & $6.5(4 \cdot 4-9 \cdot 6)$ & $26 \cdot 0 / 5 \cdot 7$ & $4.6(3 \cdot 0-6 \cdot 7)$ & $7 \cdot 0(4 \cdot 6-10 \cdot 9)$ & $7 \cdot 0 / 2 \cdot 0$ & $3.5(1 \cdot 4-7 \cdot 2)$ & $5 \cdot 0(2 \cdot 1-12 \cdot 0)$ \\
\hline $30-39$ years & $11 \cdot 0 / 5 \cdot 3$ & $2 \cdot 1(1 \cdot 0-3 \cdot 7)$ & $2.7(1.2-6.0)$ & $2.0 / 1 \cdot 5$ & $1.4(0 \cdot 2-5 \cdot 0)$ & $0.9(0.1-12.2)$ & $9 \cdot 0 / 3 \cdot 9$ & $2.3(1.1-4 \cdot 4)$ & $3.4(1 \cdot 4-8 \cdot 1)$ \\
\hline$\geq 40$ years & $15 \cdot 0 / 7 \cdot 2$ & $2 \cdot 1(1 \cdot 2-3 \cdot 4)$ & $6.8(3 \cdot 4-13 \cdot 8)$ & $0.0 / 0 \cdot 0$ & - & & $15 \cdot 0 / 7 \cdot 2$ & $2 \cdot 1(1 \cdot 2-3 \cdot 4)$ & $6.8(3.4-13.8)$ \\
\hline$P$ for heterogeneity* & & 0.0017 & 0.0048 & & 0.3168 & 0.0489 & & 0.5227 & 0.4771 \\
\hline$P$-trend* & & 0.0002 & 0.0035 & & 0.0824 & 0.0058 & & 0.2932 & 0.5172 \\
\hline \multicolumn{10}{|c|}{ Years from FPN Diaqnosis $\neq$} \\
\hline $5-9$ years & $55 \cdot 0 / 8 \cdot 0$ & $6.9(5 \cdot 2-9 \cdot 0)$ & $15 \cdot 1(11 \cdot 3-20 \cdot 1)$ & $55 \cdot 0 / 8 \cdot 0$ & $6.9(5 \cdot 2-9 \cdot 0)$ & $15 \cdot 1(11 \cdot 3-20 \cdot 1)$ & & & \\
\hline $10-19$ years & $29 \cdot 0 / 10 \cdot 0$ & $2.9(1.9-4.2)$ & $4 \cdot 2(2 \cdot 7-6 \cdot 6)$ & $29 \cdot 0 / 10 \cdot 0$ & $2.9(1.9-4.2)$ & $4 \cdot 2(2 \cdot 7-6 \cdot 6)$ & & & \\
\hline $20-29$ years & $15 \cdot 0 / 6 \cdot 0$ & $2.5(1.4-4.1)$ & $3 \cdot 8(2 \cdot 0-7 \cdot 3)$ & & & & $15 \cdot 0 / 6 \cdot 0$ & $2.5(1.4-4 \cdot 1)$ & $3 \cdot 8(2 \cdot 0-7 \cdot 3)$ \\
\hline 30-39 years & $9 \cdot 0 / 4 \cdot 1$ & $2 \cdot 2(1 \cdot 0-4 \cdot 2)$ & $5 \cdot 1(2 \cdot 1-12 \cdot 3)$ & & & & $9 \cdot 0 / 4 \cdot 1$ & $2 \cdot 2(1 \cdot 0-4 \cdot 2)$ & $5 \cdot 1(2 \cdot 1-12 \cdot 3)$ \\
\hline$\geq 40$ years & $7 \cdot 0 / 3 \cdot 0$ & $2 \cdot 3(0 \cdot 9-4 \cdot 8)$ & $12 \cdot 7(4 \cdot 8-33 \cdot 9)$ & & & & $7 \cdot 0 / 3 \cdot 0$ & $2.3(0.9-4.8)$ & $12.7(4 \cdot 8-33.9)$ \\
\hline P for heterogeneity* & & $<.0001$ & $<.0001$ & & 0.0002 & $<.0001$ & & 0.9442 & 0.1334 \\
\hline$P$-trend* & & $<.0001$ & 0.0007 & & 0.0002 & $<.0001$ & & 0.8160 & 0.0718 \\
\hline
\end{tabular}

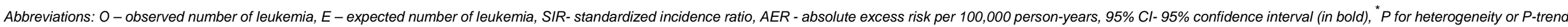

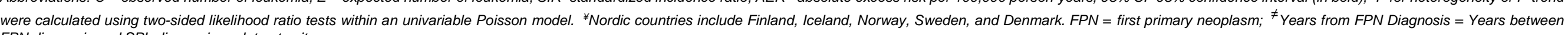
FPN diagnosis and SPL diagnosis or date at exit. 
Published in final edited form as: Eur J Cancer. 2019 Aug;117:71-83. doi: 10.1016/j.ejca.2019.05.013

Table 4: Relative risk (RR) and relative excess risk (RER) of developing a subsequent primary leukemia (SPL) by demographic and treatment factors among 69,460 five-year survivors of childhood cancer of the European PCSF study (Multivariable analyses).

\begin{tabular}{|c|c|c|}
\hline Factors & RR (95\% Cl) & $\operatorname{RER}(95 \% \mathrm{Cl})$ \\
\hline \multicolumn{3}{|l|}{ Sex } \\
\hline Male & Ref & Ref \\
\hline Female & $1 \cdot 2(0 \cdot 8-1 \cdot 7)$ & $1.0(0 \cdot 6-1 \cdot 6)$ \\
\hline$P$ for heterogeneity $\ddagger$ & 0.4328 & 0.9621 \\
\hline \multicolumn{3}{|l|}{ Type of Childhood Cancer } \\
\hline Wilms tumor & Ref & Ref \\
\hline Leukemia & $1 \cdot 1(0 \cdot 5-2 \cdot 6)$ & $0 \cdot 5(0 \cdot 2-1 \cdot 3)$ \\
\hline Hodgkin lymphoma & $2 \cdot 2(0.9-5 \cdot 4)$ & $1.6(0.5-4 \cdot 7)$ \\
\hline Non-Hodgkin lymphoma & $1 \cdot 1(0 \cdot 3-3 \cdot 2)$ & $3 \cdot 7(1 \cdot 1-12 \cdot 8)$ \\
\hline Central Nervous System & $1.0(0 \cdot 4-2 \cdot 3)$ & $0 \cdot 8(0 \cdot 3-2 \cdot 2)$ \\
\hline Neuroblastoma & $1 \cdot 2(0 \cdot 4-3 \cdot 5)$ & $2.5(0.8-7.8)$ \\
\hline Retinoblastoma & $0.7(0.2-2 \cdot 7)$ & $2 \cdot 3(0 \cdot 4-12 \cdot 8)$ \\
\hline Bone sarcoma & $0.5(0 \cdot 1-2 \cdot 1)$ & $2.5(0.6-11.6)$ \\
\hline Soft-tissue sarcoma & $1.0(0.4-2 \cdot 8)$ & $2 \cdot 2(0.7-6 \cdot 6)$ \\
\hline Other and not classifiable & $0.9(0.3-2.2)$ & $0.8(0.3-2 \cdot 5)$ \\
\hline$P$ for heterogeneity ${ }^{\ddagger}$ & 0.2471 & 0.0005 \\
\hline \multicolumn{3}{|l|}{ Age at Diagnosis of FPN } \\
\hline $0-4$ years & $1 \cdot 1(0 \cdot 5-2 \cdot 3)$ & $1.8(0.7-4.4)$ \\
\hline $5-9$ years & $1.6(0 \cdot 7-3 \cdot 3)$ & $3 \cdot 2(1 \cdot 2-8 \cdot 1)$ \\
\hline 10-14 years & $1.7(0.9-3 \cdot 5)$ & $2 \cdot 5(1 \cdot 0-6 \cdot 2)$ \\
\hline $15-19$ years & Ref & Ref \\
\hline$P$ for heterogeneity $\ddagger$ & 0.1918 & 0.0542 \\
\hline$P$-trend ${ }^{\ddagger}$ & 0.5536 & 0.9484 \\
\hline \multicolumn{3}{|l|}{ Decade of Diagnosis of FPN } \\
\hline$<1970$ & Ref & Ref \\
\hline 1970-1979 & $1 \cdot 1(0 \cdot 6-2 \cdot 2)$ & $0.9(0.4-2 \cdot 0)$ \\
\hline 1980-1989 & $1 \cdot 2(0 \cdot 6-2 \cdot 3)$ & $0.7(0.3-1.5)$ \\
\hline$\geq 1990$ & $1.4(0.7-3.0)$ & $0.5(0.2-1 \cdot 2)$ \\
\hline$P$ for heterogeneity $\ddagger$ & 0.8251 & 0.3701 \\
\hline$P$-trend ${ }^{\ddagger}$ & 0.5180 & 0.1187 \\
\hline \multicolumn{3}{|l|}{ Years from FPN Diagnosis $\neq$} \\
\hline $5-9$ years & $2 \cdot 1(0 \cdot 8-5 \cdot 4)$ & $1.4(0.4-4 \cdot 7)$ \\
\hline 10-19 years & $0.9(0.3-2.4)$ & $0.8(0 \cdot 2-2 \cdot 8)$ \\
\hline 20-29 years & $0 \cdot 8(0 \cdot 3-2 \cdot 3)$ & $1 \cdot 1(0 \cdot 3-3 \cdot 6)$ \\
\hline $30-39$ years & $0.8(0.3-2 \cdot 3)$ & $1.7(0.5-6 \cdot 1)$ \\
\hline$\geq 40$ years & Ref & Ref \\
\hline$P$ for heterogeneity $\ddagger$ & 0.0018 & 0.2498 \\
\hline$P$-trend $d^{\ddagger}$ & 0.0040 & 0.4488 \\
\hline
\end{tabular}

Abbreviations: Relative risk (RR) and relative excess risk (RER) from multivariable Poisson regression model adjusted for country, sex, type of childhood cancer, age at diagnosis, decade of diagnosis, and years from diagnosis. ${ }^{\ddagger} P$ for heterogeneity or $P$-trend were calculated using two-sided likelihood ratio tests within a multivariable Poisson model.; Ref-reference category, $95 \% \mathrm{Cl}$ - 95\% confidence interval. ${ }^{*}$ Nordic countries include Finland, Iceland, Norway, Sweden, and Denmark. FPN= first primary neoplasm; ${ }^{\neq}$Years from FPN Diagnosis $=$Years between FPN diagnosis and SPL diagnosis or date at exit. 
Table 5: SIRs and AERs per 100,000 Person-Years at risk of developing a subsequent myeloid primary leukemia (SPLM) and relative risk (RR) and relative of developing a SPLM by demographic and treatment factors among 69,460 five-year survivors of childhood cancer of the European PCSF study (Multivariable analyses).

\begin{tabular}{|c|c|c|c|c|c|}
\hline Factor & O/E & SIR (95\% CI) & RR (95\% Cl) & AER (95\% Cl) & RER (95\% Cl) \\
\hline Overall & $86 \cdot 0 / 14 \cdot 9$ & $5 \cdot 8(4 \cdot 6-7 \cdot 1)$ & & $6.3(5 \cdot 0-8.0)$ & \\
\hline P-values & & $<\cdot 0001$ & & 0.0078 & \\
\hline \multicolumn{6}{|l|}{ Sex } \\
\hline Male & $49 \cdot 0 / 8 \cdot 5$ & $5 \cdot 7(4 \cdot 3-7 \cdot 6)$ & Ref & $6.7(4.9-9.2)$ & Ref \\
\hline Female & $37 \cdot 0 / 6 \cdot 4$ & $5.8(4.1-8.0)$ & $1 \cdot 1(0 \cdot 7-1 \cdot 7)$ & $5.8(4 \cdot 1-8 \cdot 3)$ & $1 \cdot 2(0 \cdot 7-2 \cdot 1)$ \\
\hline$P$ for heterogeneity & & 0.9757 & 0.6891 & 0.5498 & 0.4485 \\
\hline \multicolumn{6}{|l|}{ Type of Childhood Cancer } \\
\hline Wilms tumor & $6 \cdot 0 / 1 \cdot 1$ & $5 \cdot 5(2 \cdot 0-12 \cdot 0)$ & Ref & $5 \cdot 1(2 \cdot 1-12 \cdot 4)$ & Ref \\
\hline Leukemia & $22 \cdot 0 / 2 \cdot 3$ & $9.6(6 \cdot 0-14.5)$ & $1 \cdot 3(0 \cdot 5-3 \cdot 3)$ & $9.0(5.8-13.9)$ & $0.5(0.2-1 \cdot 6)$ \\
\hline Hodgkin lymphoma & $16 \cdot 0 / 1 \cdot 3$ & $12 \cdot 1(6 \cdot 9-19 \cdot 6)$ & $2 \cdot 0(0 \cdot 7-5 \cdot 7)$ & $16 \cdot 8(10 \cdot 0-27 \cdot 9)$ & $1 \cdot 3(0 \cdot 3-4 \cdot 8)$ \\
\hline Non-Hodgkin lymphoma & $4 \cdot 0 / 0 \cdot 8$ & $5 \cdot 1(1 \cdot 4-13 \cdot 1)$ & $0.9(0.2-3 \cdot 2)$ & $6.0(2 \cdot 0-17 \cdot 9)$ & $3 \cdot 6(0 \cdot 7-19 \cdot 3)$ \\
\hline Central Nervous System & $16 \cdot 0 / 3 \cdot 2$ & $5 \cdot 1(2 \cdot 9-8 \cdot 2)$ & $0.9(0.3-2 \cdot 4)$ & $5.6(3 \cdot 3-9 \cdot 7)$ & $0.8(0 \cdot 2-2 \cdot 7)$ \\
\hline Neuroblastoma & $4 \cdot 0 / 0 \cdot 6$ & $7 \cdot 0(1 \cdot 9-17 \cdot 9)$ & $1 \cdot 2(0 \cdot 3-4 \cdot 2)$ & $6 \cdot 2(2 \cdot 1-17 \cdot 9)$ & $1.9(0.4-9.5)$ \\
\hline Retinoblastoma & $0 \cdot 0 / 0 \cdot 7$ & - & - & - & - \\
\hline Bone sarcoma & $1 \cdot 0 / 0 \cdot 8$ & $1.2(0.0-6.6)$ & $0.2(0.0-1 \cdot 8)$ & $0.3(0.0-41.3)$ & $1 \cdot 1(0 \cdot 1-11 \cdot 3)$ \\
\hline Soft-tissue sarcoma & $6 \cdot 0 / 1 \cdot 2$ & $5.0(1.9-11.0)$ & $1 \cdot 0(0 \cdot 3-3 \cdot 1)$ & $5 \cdot 8(2 \cdot 4-14 \cdot 3)$ & $2.9(0.7-12 \cdot 3)$ \\
\hline Other and not classifiable & $11 \cdot 0 / 3 \cdot 0$ & $3.7(1.9-6.7)$ & $0.8(0.3-2 \cdot 2)$ & $4 \cdot 2(2 \cdot 1-8 \cdot 4)$ & $0.9(0.3-3.2)$ \\
\hline$P$ for heterogeneity & & 0.0421 & 0.2457 & 0.0330 & 0.0168 \\
\hline \multicolumn{6}{|l|}{ Age at Diagnosis of FPN } \\
\hline $0-4$ years & $25 \cdot 0 / 4 \cdot 8$ & $5 \cdot 2(3 \cdot 3-7 \cdot 6)$ & $1 \cdot 7(0 \cdot 7-4 \cdot 2)$ & $4 \cdot 3(2 \cdot 8-6 \cdot 7)$ & $1.5(0.5-4 \cdot 6)$ \\
\hline $5-9$ years & $24 \cdot 0 / 3 \cdot 2$ & $7 \cdot 4(4 \cdot 7-11 \cdot 0)$ & $2 \cdot 2(1 \cdot 0-5 \cdot 2)$ & $8 \cdot 1(5 \cdot 3-12 \cdot 5)$ & $3.0(0.9-9.6)$ \\
\hline 10-14 years & $28 \cdot 0 / 4 \cdot 0$ & $6.9(4.6-10.0)$ & $2 \cdot 2(1.0-4 \cdot 9)$ & $9.5(6.4-14.2)$ & $2.9(1 \cdot 0-8 \cdot 2)$ \\
\hline 15-19 years & $9 \cdot 0 / 2 \cdot 8$ & $3.2(1.5-6 \cdot 1)$ & Ref & $4.0(1.8-8.8)$ & Ref \\
\hline$P$ for heterogeneity & & 0.1272 & 0.2192 & 0.0275 & 0.0629 \\
\hline P-trend & & 0.5240 & 0.5719 & 0.2793 & 0.8119 \\
\hline \multicolumn{6}{|l|}{ Decade of Diagnosis of FPN } \\
\hline$<1970$ & $8 \cdot 0 / 3 \cdot 7$ & $2.2(0.9-4.3)$ & Ref & $2.4(0.9-6.2)$ & Ref \\
\hline 1970-1979 & $15 \cdot 0 / 3 \cdot 6$ & $4 \cdot 2(2 \cdot 4-7 \cdot 0)$ & $1 \cdot 6(0 \cdot 6-4 \cdot 2)$ & $4.7(2 \cdot 6-8 \cdot 3)$ & $1.9(0.5-7 \cdot 2)$ \\
\hline 1980-1989 & $25 \cdot 0 / 4 \cdot 4$ & $5.7(3.7-8.5)$ & $1.5(0.6-3.9)$ & $5.7(3.7-8 \cdot 8)$ & $0.9(0.2-3 \cdot 7)$ \\
\hline$\geq 1990$ & $38 \cdot 0 / 3 \cdot 3$ & $11 \cdot 4(8 \cdot 1-15 \cdot 7)$ & $2 \cdot 0(0 \cdot 7-5 \cdot 3)$ & $10 \cdot 1(7 \cdot 3-14 \cdot 1)$ & $0.5(0.1-2 \cdot 0)$ \\
\hline$P$ for heterogeneity & & $<-0001$ & 0.5264 & 0.0064 & 0.1036 \\
\hline P-trend & & $<.0001$ & 0.4096 & 0.0006 & 0.0520 \\
\hline \multicolumn{6}{|l|}{ Years from FPN Diagnosis $\neq$} \\
\hline 5-9 years & $42 \cdot 0 / 2 \cdot 6$ & $\begin{array}{l}16 \cdot 0(11 \cdot 5- \\
21 \cdot 6)\end{array}$ & $2 \cdot 6(0 \cdot 8-9 \cdot 1)$ & $12 \cdot 6(9 \cdot 2-17 \cdot 3)$ & $0.5(0 \cdot 1-3 \cdot 0)$ \\
\hline 10-19 years & $24 \cdot 0 / 4 \cdot 9$ & $4.9(3 \cdot 1-7 \cdot 2)$ & $0.8(0.2-2 \cdot 9)$ & $4 \cdot 2(2 \cdot 7-6 \cdot 6)$ & $0.2(0 \cdot 0-1 \cdot 6)$ \\
\hline 20-29 years & $13 \cdot 0 / 3 \cdot 8$ & $3.4(1.8-5.9)$ & $0.7(0.2-2 \cdot 4)$ & $3.9(2.0-7.4)$ & $0.3(0 \cdot 0-1 \cdot 8)$ \\
\hline 30-39 years & $3 \cdot 0 / 2 \cdot 3$ & $1.3(0.3-3.9)$ & $0.3(0.1-1.5)$ & $0.7(0.1-7.5)$ & $1 \cdot 1(0 \cdot 2-8 \cdot 6)$ \\
\hline$\geq 40$ years & $4 \cdot 0 / 1 \cdot 3$ & $3.1(0.8-7.9)$ & Ref & $8.6(2.6-28.4)$ & Ref \\
\hline$P$ for heterogeneity & & $<.0001$ & $<.0001$ & $<.0001$ & $0 \cdot 1056$ \\
\hline P-trend & & $<.0001$ & $<.0001$ & 0.0001 & 0.9415 \\
\hline \multicolumn{6}{|c|}{$\begin{array}{l}\text { Abbreviations: O- observed number of leukemia, E- expected number of leukemia, SIR-standardized incidence ratio, AER - absolute excess risk } \\
\text { per 100,000 person-years, } 95 \% \mathrm{Cl} \text { - } 95 \% \text { confidence interval (in bold), P for heterogeneity or } P \text {-trend were calculated using two-sided likelihood ratio } \\
\text { tests within an univariable Poisson model. Relative risk (RR) and relative excess risk (RER) from multivariable Poisson regression model adjusted }\end{array}$} \\
\hline \multicolumn{6}{|c|}{$\begin{array}{l}\text { for country, sex, type of childhood cancer, age at diagnosis, decade of diagnosis, and years from diagnosis. }{ }^{\ddagger} P \text { for heterogeneity or } P \text {-trend were } \\
\text { calculated using two-sided likelihood ratio tests within a multivariable Poisson model.; Ref- reference category, } 95 \% \mathrm{Cl} \text { - } 95 \% \text { confidence interval. }\end{array}$} \\
\hline${ }^{*}$ Nordic countries include Finland, & & 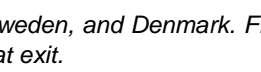 & & $\neq$ & \\
\hline
\end{tabular}

